\title{
Characteristics of Resistance Spot Welded Ti6A14V Titanium Alloy Sheets
}

\author{
Xinge Zhang ${ }^{1}$, Jiangshuai Zhang ${ }^{1}$, Fei Chen ${ }^{1}$, Zhaojun Yang ${ }^{1}$ and Jialong $\mathrm{He}^{1,2, *}$ \\ 1 School of Mechanical Science and Engineering, Jilin University, Changchun 130025, China; \\ zhangxinge@jlu.edu.cn (X.Z.); 18343126188@163.com (J.Z.); chenfeicn@jlu.edu.cn (F.C.); \\ yangzj@jlu.edu.cn (Z.Y.) \\ 2 College of Computer Science and Technology, Jilin University, Changchun 130012, China \\ * Correspondence: hjl.star@163.com; Tel.: +86-0431-8509-5839
}

Received: 4 September 2017; Accepted: 3 October 2017; Published: 12 October 2017

\begin{abstract}
Ti6Al4V titanium alloy is applied extensively in the aviation, aerospace, jet engine, and marine industries owing to its strength-to-weight ratio, excellent high-temperature properties and corrosion resistance. In order to extend the application range, investigations on welding characteristics of Ti6Al4V alloy using more welding methods are required. In the present study, Ti6Al4V alloy sheets were joined using resistance spot welding, and the weld nugget formation, mechanical properties (including tensile strength and hardness), and microstructure features of the resistance spot-welded joints were analyzed and evaluated. The visible indentations on the weld nugget surfaces caused by the electrode force and the surface expulsion were severe due to the high welding current. The weld nugget width at the sheets' faying surface was mainly affected by the welding current and welding time, and the welded joint height at weld nugget center was chiefly associated with electrode force. The maximum tensile load of welded joint was up to $14.3 \mathrm{kN}$ in the pullout failure mode. The hardness of the weld nugget was the highest because of the coarse acicular $\alpha^{\prime}$ structure, and the hardness of the heat-affected zone increased in comparison to the base metal due to the transformation of the $\beta$ phase to some fine acicular $\alpha^{\prime}$ phase.
\end{abstract}

Keywords: Ti6Al4V titanium alloy; resistance spot welding; mechanical properties; microstructure

\section{Introduction}

Ti6Al4V titanium alloy is widely used in the aerospace, marine, pressure vessel, and chemical industries, as well as for surgical implant, etc., owing to its unique properties, such as a high strength-to-weight ratio, excellent high-temperature properties and corrosion resistance; furthermore, the usage of Ti6Al4V alloy accounts for over $50 \%$ of the total titanium alloy tonnage, globally [1-5]. Many welding methods, such as tungsten inert gas welding (TIG) [6,7], laser welding [8], electron beam welding [9], plasma arc welding [10], line friction welding [11-13], and friction stir welding [14,15] have been employed to weld titanium alloy in previous investigations.

Based on the existing literature, the TIG welding process is always used to weld butt joints of Ti6Al4V titanium alloy, but the weld structure is coarse, inducing high welding residual stress and distortion. The laser welding and electron beam welding processes are considered to be better replacements for the TIG welding process due to their advantages of high welding speed and slight welding distortion $[6,7]$. But the laser welding and electron beam welding processes are more suitable to weld butt joints than lap joints due to the high depth-to-width ratio penetration ability. Even more importantly, the equipment investment and operating cost are high [6-9]. The plasma arc welding process is a high-energy beam welding technology, and is utilized to weld the butt joint of thicker titanium alloy plate, which is similar to the laser welding process [10]. Line friction welding has been used to join titanium alloy bulk plates or parts because of its own process principles and 
features [11-13]. The brazing process is easy to implement for joining titanium alloy, but this process must be carried out under vacuum conditions, and a long welding time is normally required $[14,15]$. In the last three decades, friction stir welding has emerged as a new welding technology, and was adapted for welding thin sheets, not only for butt joints but also lap joints. However, owing to the high melting point of titanium alloy and the high contact forces between metal sheets and the friction tool, the choice of friction tool material is difficult and limited [16-18].

Resistance spot welding (RSW) is widely used for lap joint assembly of two metal sheets, especially in the automotive industry, mainly owing to its high production efficiency, low operation cost and high degree of automation [19]. During the resistance spot welding process, the metal sheets are assembled as lap joints and the lap joint is compressed by two water-cooled electrodes. Then, the welding current is applied to metal sheets through the electrodes provided by the welding power. Due to the large contact resistance at the faying surface of the metal sheets, the Joule heat generates mainly at the faying surface, and then the metal sheets melt in a short time [20]. Finally, when the welding current supply is turned off, the melted metal solidifies, resulting in the joining of the metal sheets. Resistance spot welding has been employed for welding steel, aluminum alloys, magnesium alloys, nickel alloys, copper alloys, pure titanium, and dissimilar metals [21-25]. However, to the best of the authors' knowledge, there are few reports on resistance spot welding of Ti6Al4V titanium alloy sheets in the previous literature. In the present study, assembling the Ti6Al4V titanium alloy sheets into lap joints was performed by resistance spot welding, and then the welding characteristics, including weld nugget formation and the effects of the welding parameters on it, were investigated. Meanwhile, the mechanical properties, including tensile strength, hardness, and microstructure features, of the typical spot-welded joint were evaluated and analyzed in detail.

\section{Materials and Methods}

In this study, the base metal is Ti6Al4V titanium alloy sheet and the sheet thickness is $1 \mathrm{~mm}$. The chemical composition of the base metal is listed in Table 1 . The schematic diagram of the resistance spot welding process is illustrated in Figure 1a, and the overlap joint configuration and dimensions of the specimen are shown in Figure 1b. Before welding, the specimens were cleaned to remove surface contamination and oxides. The resistance spot welding of the overlap joints was carried out using a DN-100 resistance spot welding machine (Denyo Kunshan Inc., Kunshan, China), and the tip diameter of $\mathrm{Cu}-\mathrm{Cr}$ alloy electrodes was $6 \mathrm{~mm}$. The resistance spot welding parameters include the welding current, welding time, and electrode force, and the experimental conditions are shown in Table 2. The unit of welding time is the cycle $(1$ cycle $=0.02 \mathrm{~s})$, and the welding current is continuous and constant in each cycle. A schematic diagram of the applied of welding current is shown in Figure 2.

Table 1. Chemical composition of Ti6Al4V titanium alloy (wt \%).

\begin{tabular}{ccccccccc}
\hline Component & Al & V & Fe & Si & O & C & N & Ti \\
\hline wt $\%$ & 6.15 & 3.96 & 0.3 & 0.15 & 0.2 & 0.02 & 0.01 & Balance \\
\hline
\end{tabular}

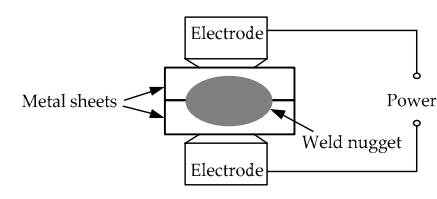

(a)

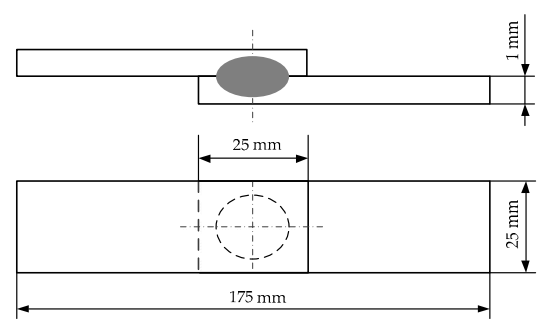

(b)

Figure 1. (a) Schematic diagram of resistance spot welding process; and (b) configuration and dimensions of specimen. 
Table 2. Experimental conditions.

\begin{tabular}{cccc}
\hline Condition & Welding Current (kA) & Welding Time (Cycle ${ }^{\mathbf{1}}$ ) & Electrode Force (kN) \\
\hline Set 1 & $7,8,9,10,11$ & 12 & 3 \\
Set 2 & 9 & $4,8,12,16,20$ & 3 \\
Set 3 & 9 & 12 & $2,3,4,5$ \\
\hline
\end{tabular}

${ }^{1} 1$ cycle $=0.02 \mathrm{~s}$.

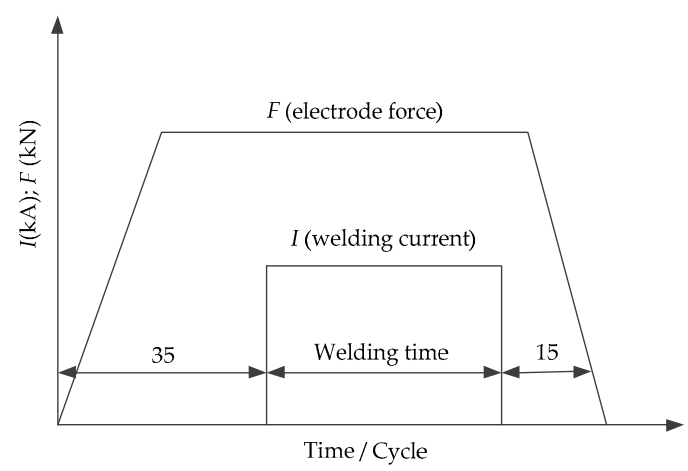

Figure 2. Schematic diagram of the applied of welding current.

After welding, the welded joints were sectioned along the spot weld nugget center, followed by mounting, polishing, and etching for microstructure observation. The etch solution consisted of $1 \mathrm{vol} \% \mathrm{HCl}, 1.5 \mathrm{vol} \% \mathrm{HF}, 2.5 \mathrm{vol} \% \mathrm{HNO}_{3}$, and $95 \mathrm{vol} \% \mathrm{H}_{2} \mathrm{O}$. The microstructure was examined using an Eclipse E200 optical microscope (Nikon Instruments (Shanghai) Co., Ltd., Shanghai, China) and S-4700 scanning electron microscopy (SEM; Hitachi High-Technologies in China, Suzhou, China). The hardness measurement was performed on the cross-sections of spot welded joints using a HV-30 hardness machine (Shanghai Tuming Instrument Co., Ltd., Shanghai, China) with a 5 kgf test load. The tensile shear test was carried out by means of Instron 5500R material tensile machine (Instron, Division of Illinois Tool Works Inc., Norwood, MA, USA). The fracture surface morphology of spot welded joints was observed using SEM.

\section{Results}

\subsection{Weld Nugget Formation}

The typical appearances of resistance spot welded Ti6Al4V titanium alloy joints are shown in Figure 3. Visible indentations could be seen on the weld nugget surfaces for all welded joints, which is a local plastic deformation on the sheets' surface owing to the high temperature and applied electrode force at the faying surface between electrode and sheet. During the resistance spot welding process, the expulsion on the weld nugget surface was an unfavorable phenomenon, and is mainly associated with the welding current. Although there was no expulsion on the weld nugget surface when the welding current was no more than $9 \mathrm{kA}$, a slight expulsion appeared along the edge of the weld nugget while the welding current was increased to $10 \mathrm{kA}$, as shown in Figure $3 \mathrm{~b}$. As seen in Figure $3 \mathrm{c}$, when the welding current was increased to $11 \mathrm{kA}$, the expulsion became very severe. It is well known that severe expulsion may decrease the surface quality of the spot weld and cause adhesion between the electrode and specimen surfaces. Therefore, a low-level welding current should be chosen to suppress the expulsion on the weld nugget surface, thus improving the spot weld quality and electrode life. 


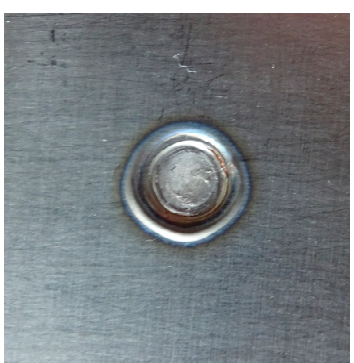

(a)

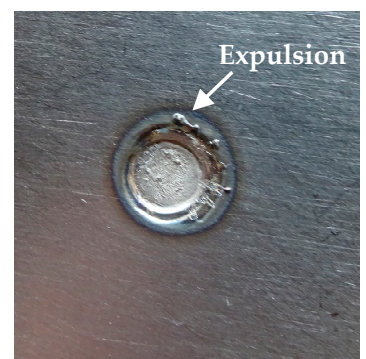

(b)

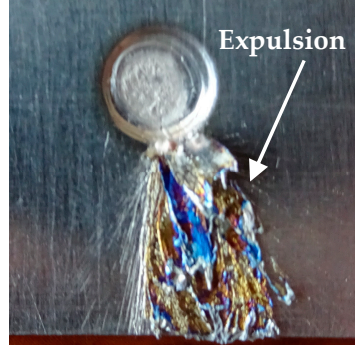

(c)

Figure 3. Appearances of resistance spot welded joints with different welding currents: (a) $9 \mathrm{kA}$; (b) $10 \mathrm{kA}$; and (c) $12 \mathrm{kA}$.

Figure 4 illustrates the typical cross-section of spot welded joint with $9 \mathrm{kA}$ welding current, 12 cycles welding time, and $3 \mathrm{kN}$ electrode force. The joint of the resistance spot welded Ti6Al4V titanium alloy presents characteristics such as a large weld nugget width at the faying surface and full penetration in the weld nugget center. In this study, because the thickness of the Ti6Al4V titanium alloy sheet was only $1 \mathrm{~mm}$, when the high-level welding heat input (high welding current or welding time) was used to obtain enough weld nugget width at the faying surface, this resulted in full melting from the faying surfaces outward to the electrodes. However, the two types of materials (metal sheet: Ti6Al4V alloy; electrode: $\mathrm{Cu}-\mathrm{Cr}$ alloy) exhibited large differences in physical and chemical properties, which made the adhesion between them difficult, and thus no significant contamination of or damage to the electrodes occurred. A spot-welded joint consists of the weld nugget, the heat affected zone (HAZ), and the base metal. A distinct boundary exists between three different regions, and the HAZ is located between the weld nugget and the base metal. The indentations on the top surface and bottom surface of the welded joint are distinct, which causes the thickness of weld zone to decrease, especially in the weld center. In general, the spot weld morphology significantly affects the welded joint strength, and then two geometric dimensions are extracted as the evaluation index; namely, the weld nugget width $(\mathrm{W})$ at the faying surface, and the welded joint height $(\mathrm{H})$ in the spot weld center, as shown in Figure 4.

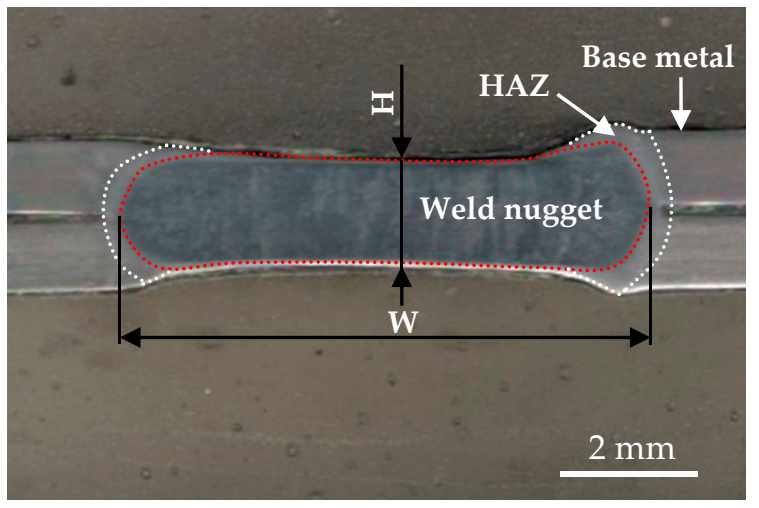

Figure 4. Typical cross-section of the spot welded joint.

Figure 5 shows the effect of the single welding parameter on the weld nugget width (W) at the faying surface and the welded joint height $(\mathrm{H})$ in the spot weld center.

In resistance spot welding, the welding current flows from the electrode through the metal sheets' faying surface, with electrical resistance heat primarily being generated at the faying surface. Then, the metal sheets around the faying surface are heated and melted, which finally results in the formation 
of the weld nugget. The weld nugget morphology is mainly controlled by this heat generation. The heat generation can be determined as:

$$
Q=I^{2} R t
$$

where $Q$ is the heat generation in joules, $I$ is the welding current in amperes, $R$ is the contact resistance in ohms, and $t$ is the welding time in seconds [19]. As seen in Figure 5a, according to the Equation (1), when the welding current was increased from $7 \mathrm{kA}$ to $10 \mathrm{kA}$, the heat generation increased correspondingly, which caused the weld nugget width (W) to increase from $6.3 \mathrm{~mm}$ to $7.9 \mathrm{~mm}$; but, when the welding current was increased to $11 \mathrm{kA}$, the weld nugget width (W) tended to decrease, owing to the severe expulsion shown in Figure 3c. Since the higher welding current results in larger heat generation and a longer time above the melting temperature of the sheet material, the indentation is deeper. On the other hand, a higher welding current leads to severe expulsion. Thus, the welded joint height $(\mathrm{H})$ decreased with the increase of the welding current, as shown in Figure 5 a.

As seen in Figure $5 b$, when the welding time was increased from 4 cycles to 12 cycles, the weld nugget width (W) evidently increased due to higher heat generation, in accordance with Equation (1); however, if the welding time continues to increase, the weld nugget width (W) has no obvious change, owing to the basic balance between the heat input rate and heat output rate. The longer the welding time was, the longer the electrode force applied, which resulted in deeper indentation, following which the welded joint height $(\mathrm{H})$ slightly decreased with the increase of welding time.

As seen in Figure $5 c$, when the electrode force is increased from $2 \mathrm{kN}$ to $5 \mathrm{kN}$, the weld nugget width (W) and welded joint height $(\mathrm{H})$ all increase at first, and then obviously reduce. When the electrode force was $2 \mathrm{kN}$, the two metal sheets were not compressed tightly by the electrode force, leading to a high current density passing through the weld nugget zone, and then resulting in severe expulsion at the faying surface between the two metal sheets, as shown in Figure 6. The severe expulsion at the faying surface was of no benefit to the growth of the weld nugget. While the electrode force increased to $3 \mathrm{kN}$, there was no evident expulsion; therefore, the weld nugget width (W) and welded joint height $(\mathrm{H})$ had all increased, compared with of the values for $2 \mathrm{kN}$ electrode force. If the electrode force continues to increase, two metal sheets are compressed tightly, and the current density passing through the weld nugget zone decreases, causing the weld nugget width $(\mathrm{W})$ to sharply reduce. Meanwhile, the larger the electrode force, the deeper the indentation, as the welded joint height $(\mathrm{H})$ decreased, as seen in Figure 5c.

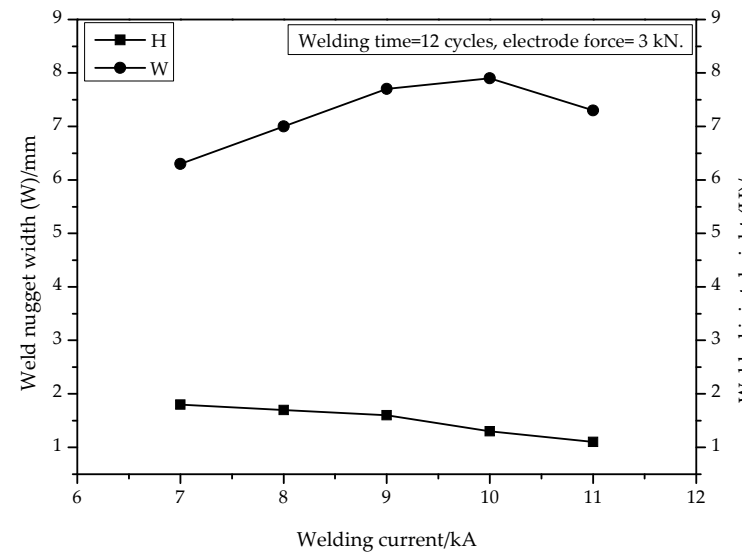

(a)

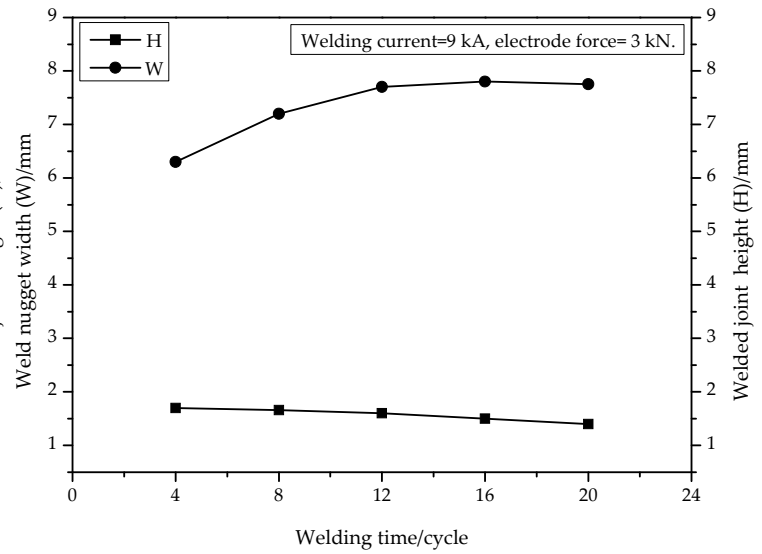

(b)

Figure 5. Cont. 


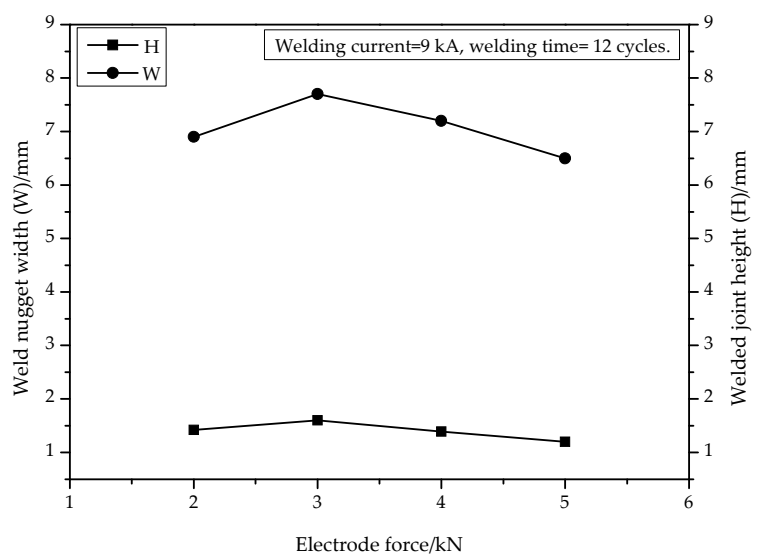

(c)

Figure 5. Effects of welding parameters on the spot weld morphology (W, H): (a) Welding current; (b) welding time; and (c) electrode force.

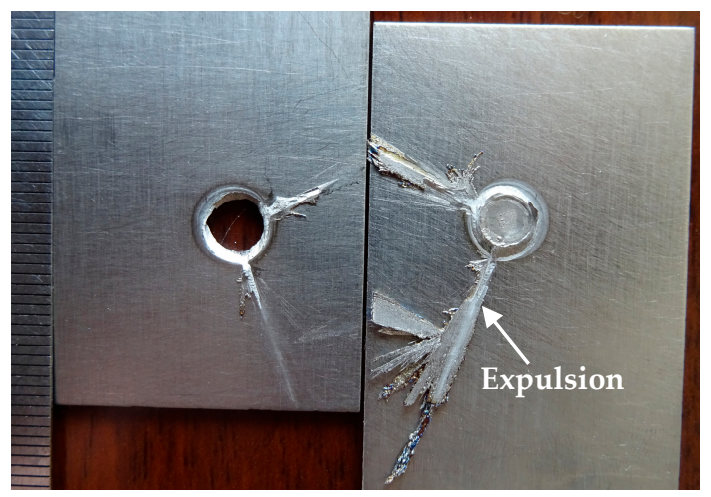

Figure 6. Expulsion at the faying surface between two metal sheets.

\subsection{Tensile Strength}

The tensile shear test results demonstrated that the welding parameters had a direct effect on the tensile strength of tensile shear test specimens. The relationships between the weld parameters and tensile shear load are given in Figure 7. In this investigation, the maximum tensile load of the specimen was up to $14.3 \mathrm{kN}$ with the favorable welding parameters: $9 \mathrm{kA}$ welding current, 12 cycles welding time, and $3 \mathrm{kN}$ electrode force.

The tensile loads of specimens increase fast from $7 \mathrm{kA}$ up to $9 \mathrm{kA}$ welding current, where the maximum tensile load occurs, as shown in Figure 7a. The higher welding current caused severe expulsion and deep indentation, so the tensile load of the specimen decreased. As shown in Figure $7 \mathrm{~b}$, with the increase in welding time, the tensile loads of specimens increased at first, and then obviously tended to a constant level, which is consistent with the influence of welding time on weld nugget width $(\mathrm{W})$. As seen in Figure 7c, when the electrode force is increased from $2 \mathrm{kN}$ to $3 \mathrm{kN}$, the tensile loads of the specimens increase, owing to the increase of the weld nugget width (W). However, when the electrode force continues to increase, the tensile loads of the specimens sharply decrease due to the deeper indentation, resulting in the lower welded joint height $(\mathrm{H})$. 


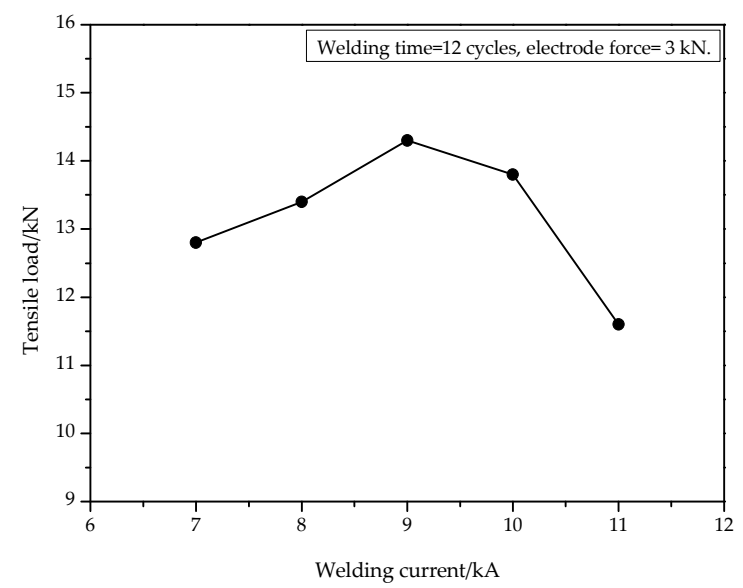

(a)

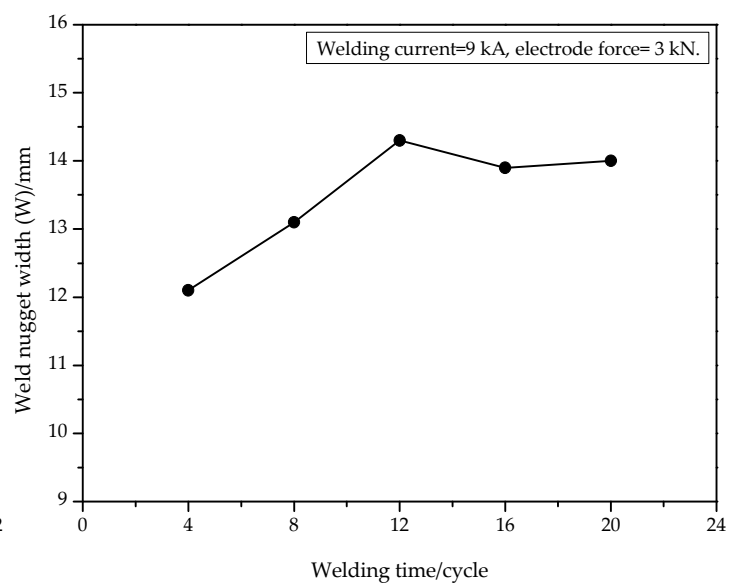

(b)

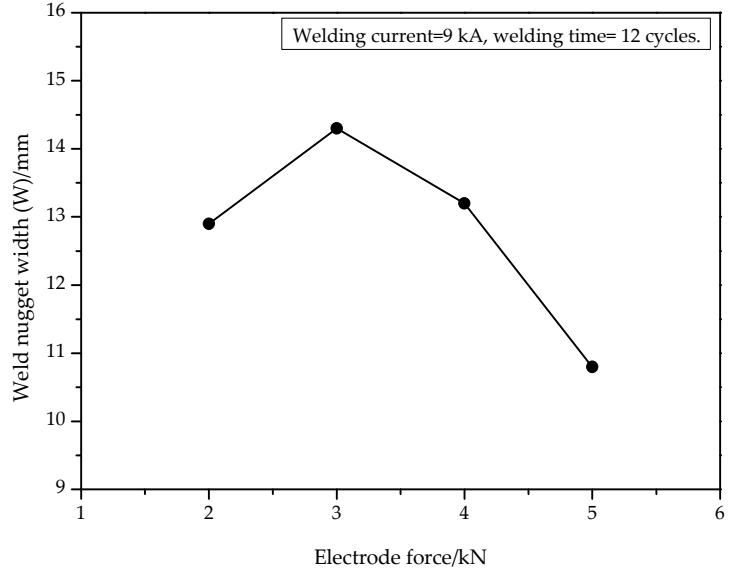

(c)

Figure 7. Relations between welding parameters and tensile shear load: (a) Welding current; (b) welding time; and (c) electrode force.

During the tensile shear test, the partial interfacial failure (PIF) mode and pullout failure (PF) mode were observed, as shown in Figures 8 and 9. For the partial interfacial failure mode, the tensile testing crack initiated at the two metal sheets faying surface owing to the stress concentration resulting from the notch at the periphery of the weld nugget shown in Figure 10a, and then propagated along the weld nugget circumference due to the electrode indentation resulting in the lower welded joint height (H). The fracture surface morphology of the tear weld nugget was observed at higher magnification with SEM. The upper part of the fracture surface displayed a brittle fracture feature, as shown in Figure $8 \mathbf{b}$, and the lower part of fracture surface displayed a ductile fracture feature, as shown in Figure 8c. For the pullout failure mode, the tensile testing crack also originated at the two metal sheets' faying surface, but the crack propagated along the vertical thickness direction, and then the tensile testing specimen broke in the normal fracture mode, as shown in Figure 9a. The fracture surface shows dimple features, as shown in Figure 9b. In this investigation, the transition from the PIF mode to the PF mode was determined by the electrode indentation owing to enough weld nugget width (W) for all the welded joints, and if the welded joint height $(\mathrm{H})$ was used to replace the electrode indentation as an evaluation index, the critical value of the welded joint height $(\mathrm{H})$ was $1.55 \mathrm{~mm}$. 


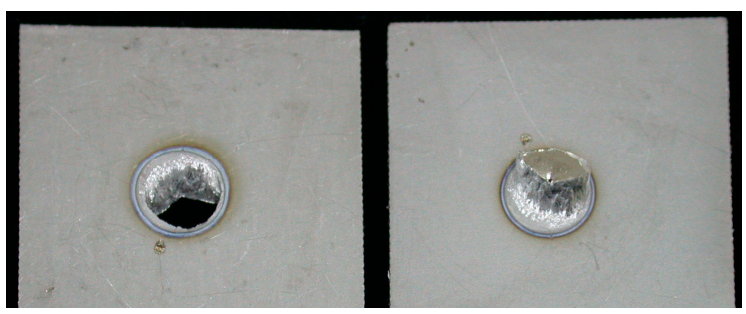

(a)

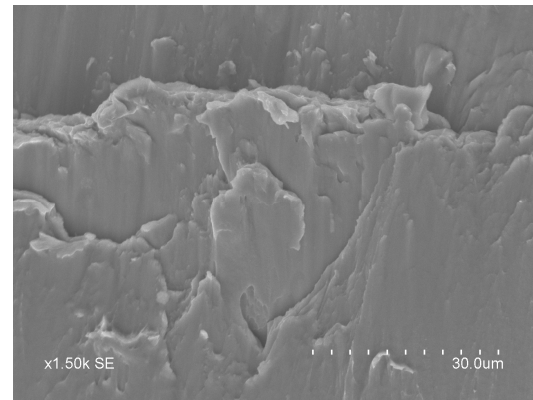

(b)

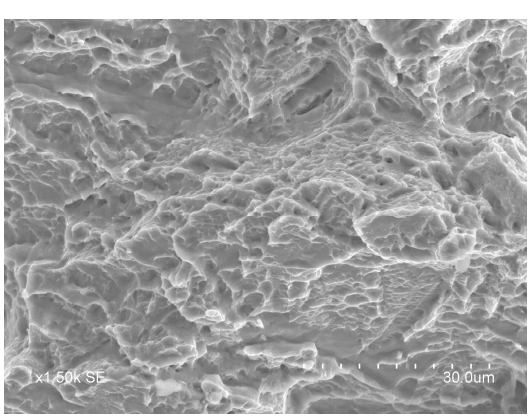

(c)

Figure 8. Partial interfacial failure mode: (a) Fracture appearance; (b) SEM (scanning electron microscopy) observation of the upper part of fracture surface; (c) SEM observation of the lower part of fracture surface.

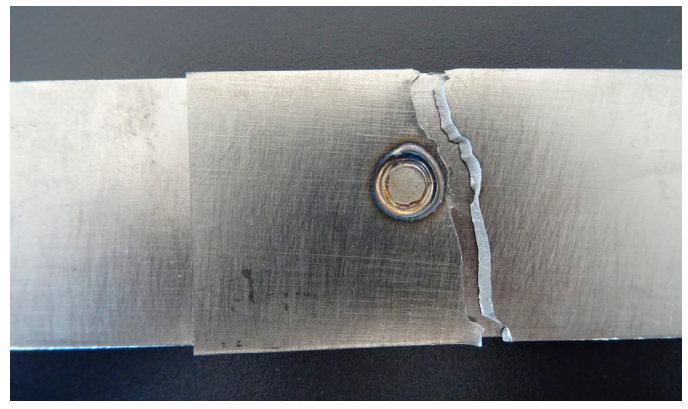

(a)

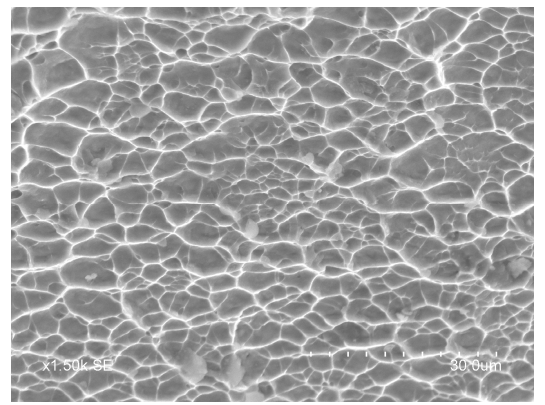

(b)

Figure 9. Pullout failure mode: (a) Fracture appearance; and (b) SEM observation of the fracture surface.

\subsection{Microstructure}

Figure 10 indicates the typical microstructure features of a resistance spot welded Ti6Al4V titanium alloy joint obtained using $9 \mathrm{kA}$ welding current, 12 cycles welding time, and $3 \mathrm{kN}$ electrode force. The welded joint consists of three main zones-weld nugget, HAZ and base metal-and there is usually a clear delineation between the three zones, owing to the different microstructure feature. As seen in Figure 10a, there is an obvious notch in the edge of the weld nugget at the two metal sheets' faying surface resulting from the insufficient heat input in this region, which is always the initiation of a crack under load conditions. The microstructure of the base metal consists of a small percentage of $\beta$ phase distributed at the elongated $\alpha$ phase grain boundary, which is the typical anneal structure for the $\alpha+\beta$ titanium alloy, as shown in Figure 10b. The microstructure in the HAZ is a mixture of primary $\alpha$, primary $\beta$ and transformation of $\beta$ phase to some fine acicular $\alpha^{\prime}$ phase, as shown in Figure 10c. It could be inferred that the HAZ maximum temperature excursion was below the temperature of the $\beta$ phase transit at $980-1000{ }^{\circ} \mathrm{C}$ and the cool rate was relatively rapid in this region due to its being close to the base metal. The grain structure of the weld nugget was coarsened compared with that of the base metal, owing to the large heat input and the slower cool rate in the weld nugget. In the 
weld nugget zone, the $\beta$ phase structure entirely transformed to a coarse acicular martensite $\alpha^{\prime}$ phase, as shown in Figure 10d.

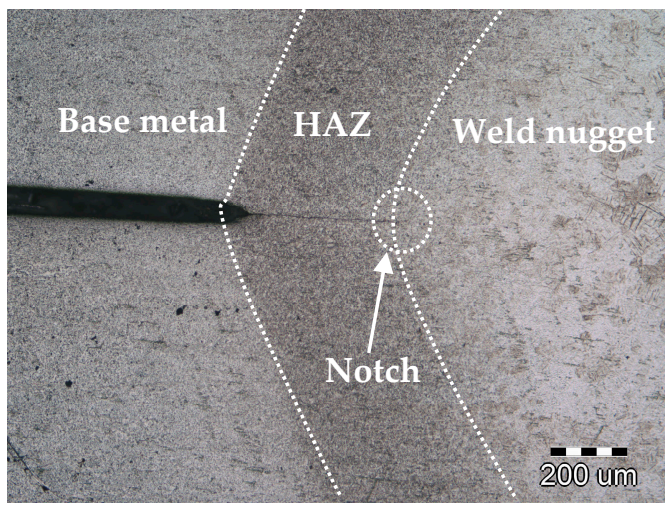

(a)

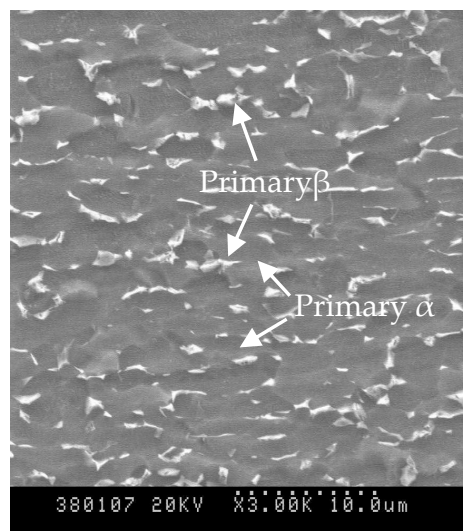

(b)

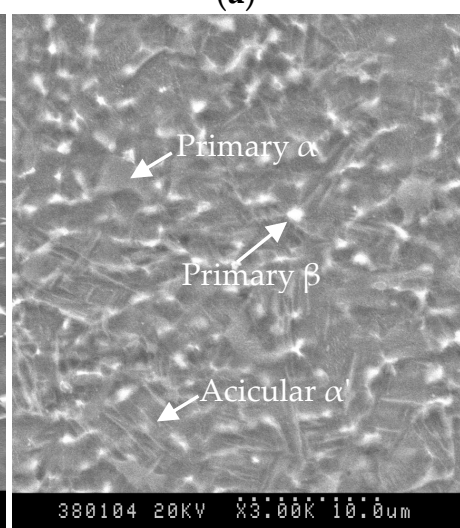

(c)

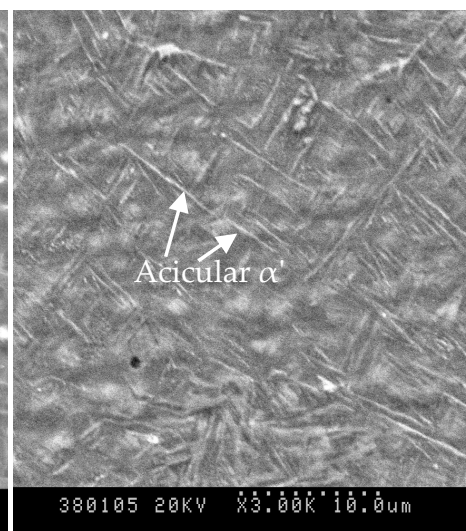

(d)

Figure 10. Microstructure of: (a) Three zones; (b) base metal; (c) HAZ (heat affected zone); and (d) weld nugget zone.

\subsection{Hardness Distribution}

Hardness measurements were carried out on the cross-sections of the typical resistance spot welded joint obtained using the optimal welding parameters using $9 \mathrm{kA}$ welding current, 12 cycles welding time and $3 \mathrm{kN}$ electrode force. The measurements were performed along two directions, as illustrated in Figure 11a,b. The measurement results are indicated in Figure 11c,d, respectively. The average hardness of the base metal is $300 \mathrm{HV}$. The hardness of HAZ increases to about $318 \mathrm{HV}$. The average hardness of the weld nugget is the highest in the welded joint because of the acicular martensite microstructure in this region, shown in Figure 10d, and the peak hardness of the weld nugget reaches about $358 \mathrm{HV}$. Along the vertical measurement location, the hardness varies slightly, except for two location points close to the top and bottom surfaces, owing to the nearly full penetration, as shown in Figure 11d. Therefore, during the tensile test, because the weld nugget width at the faying surface was wide enough and the indentation was slight, a tensile testing crack initiated at the two metal sheets' faying surface and propagated along the vertical thickness direction in the HAZ owing to the lower hardness compared with weld nugget zone. 


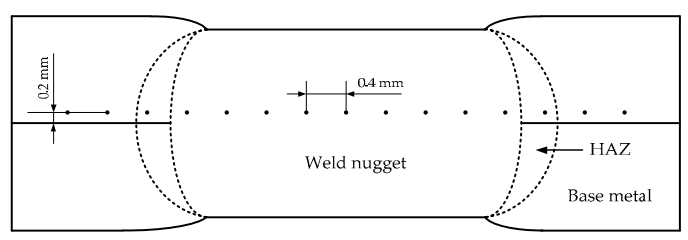

(a)

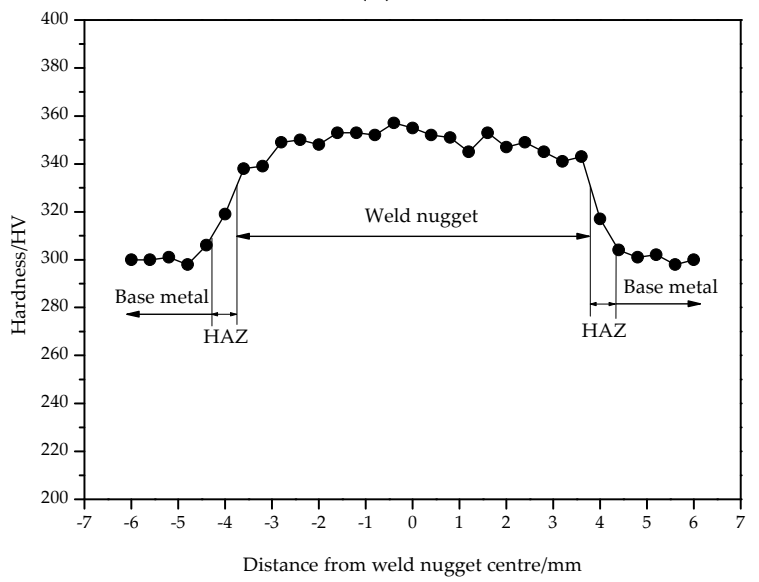

(c)

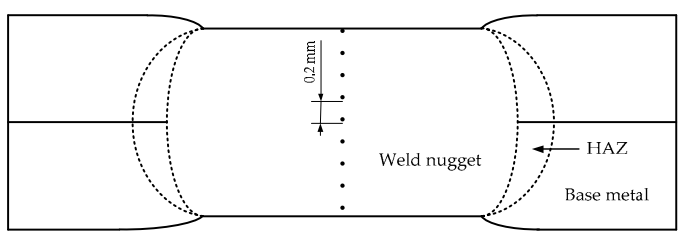

(b)

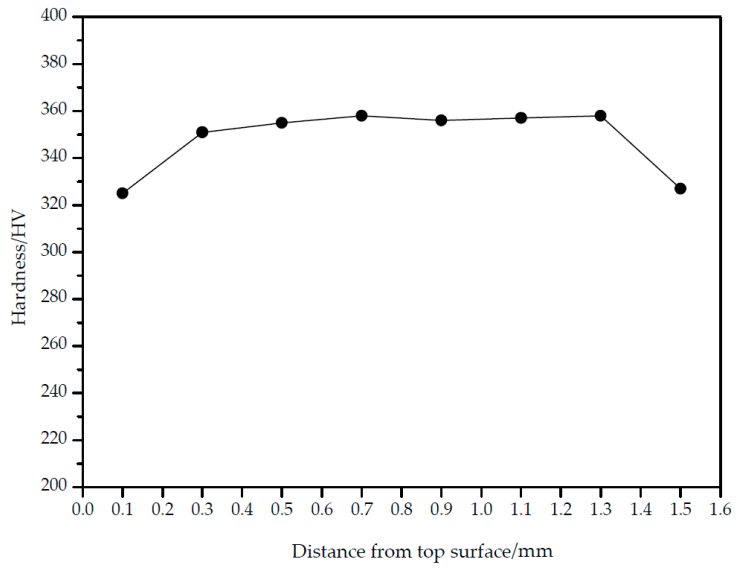

(d)

Figure 11. (a) Horizontal measurement location; (b) vertical measurement location; (c) horizontal hardness distribution; and (d) vertical hardness distribution.

\section{Conclusions}

Ti6Al4V titanium alloy sheets were well joined using resistance spot welding, and the welding characteristics were investigated in detail. The conclusions of this study are presented as follows:

(1) The visible indentations resulting from a local plastic deformation on the sheets' surface were caused by the electrode force at the faying surface between electrode and sheet. The expulsion on the weld nugget surface was mainly associated with the welding current. Although there was no expulsion on the weld nugget surface when the welding current was no more than $9 \mathrm{kA}$, with the welding current raised to $11 \mathrm{kA}$, the expulsion became very severe.

(2) With an increase in welding current, the weld nugget width (W) increased, and the welded joint height $(\mathrm{H})$ at the weld nugget center decreased. When the welding time was increased from 4 cycles to 20 cycles, the weld nugget width (W) at first increased, and then changed less obviously. When the electrode force was increased from $2 \mathrm{kN}$ to $5 \mathrm{kN}$, the weld nugget width (W) and welded joint height $(\mathrm{H})$ all increased at first, and then evidently decreased.

(3) The maximum tensile load of the welded joint was up to $14.3 \mathrm{kN}$. Two types of failure mode were observed: partial interfacial failure and pullout failure. In this investigation, the transition from PIF mode to PF mode was determined by the electrode indentation owing to enough weld nugget width $(\mathrm{W})$ for all welded joints. The critical value of the welded joint height $(\mathrm{H})$ was $1.55 \mathrm{~mm}$.

(4) The welded joint mainly consisted of three zones-weld nugget, HAZ and base metal-and there was an obvious notch in the edge of the weld nugget at the two metal sheets' faying surface resulting from the insufficient heat input in this region. In the weld nugget zone, it could be seen that the $\beta$ phase structure entirely transformed to a coarse acicular martensite $\alpha^{\prime}$ phase; therefore, the hardness of the weld nugget was the highest. The microstructure in HAZ was a mixture of primary $\alpha$, primary $\beta$, and a transformation of the $\beta$ phase to fine acicular $\alpha^{\prime}$ phase, resulting in the increase of hardness in the HAZ compared with the base metal.

Acknowledgments: The work was financially supported by the Jilin Scientific and Technological Development Program (20160520055JH). 
Author Contributions: Xinge Zhang designed the experiments, performed the experiments, analyzed the data and wrote the paper. Jiangshuai Zhang and Fei Chen performed the microstructure observation and hardness measurement experiments. Zhaojun Yang and Jialong He contributed to the discussion and interpretation of the experiment results.

Conflicts of Interest: The authors declare no conflict of interest.

\section{References}

1. Lütjering, G.; Williams, J.C. Titanium, 2nd ed.; Springer: Berlin/Heideberg, Germany, 2007; pp. 449-450.

2. Cao, X.; Jahazi, M. Effect of welding speed on butt joint quality of Ti6Al4V alloy welded using a high-power Nd:YAG laser. Opt. Lasers Eng. 2009, 47, 1231-1241. [CrossRef]

3. Köse, C.; Karaca, E. Robotic Nd:YAG Fiber laser welding of Ti-6Al-4V alloy. Metals 2017, 7, 221. [CrossRef]

4. Attanasio, A.; Gelfi, M.; Pola, A.; Ceretti, E.; Giardini, C. Influence of material microstructures in micromilling of Ti6Al4V alloy. Materials 2013, 6, 4268-4283. [CrossRef] [PubMed]

5. Akman, E.; Demir, A.; Canel, T.; Sınmazçelik, T. Laser welding of Ti6Al4V titanium alloys. J. Mater. Process. Technol. 2009, 209, 3705-3713. [CrossRef]

6. Gao, X.L.; Zhang, L.J.; Liu, J.; Zhang, J.X. Comparison of tensile damage evolution in Ti6A14V joints between laser beam welding and gas tungsten arc welding. J. Mater. Eng. Perform. 2014, 23, 4316-4327. [CrossRef]

7. Qi, Y.L.; Deng, J.; Hong, Q.; Zeng, L.Y. Electron beam welding, laser beam welding, gas tungsten arc welding of titanium sheet. Mater. Sci. Eng. A 2000, 280, 177-181.

8. Caiazzo, F.; Curcio, F.; Daurelio, G.; Memola Capece Minutolo, F. Ti6Al4V sheets lap and butt joints carried out by $\mathrm{CO}_{2}$ laser: Mechanical and morphological characterization. J. Mater. Process. Technol. 2004, 149, 546-552. [CrossRef]

9. Prasad Rao, K.; Angamuthu, K.; Bala Srinivasan, P. Fracture toughness of electron beam welded Ti6Al4V. J. Mater. Process. Technol. 2008, 199, 185-192.

10. Chen, J.C.; Pan, C.X. Welding of Ti-6Al-4V alloy using dynamically controlled plasma arc welding process. Trans. Nonferr. Met. Soc. China 2011, 21, 1506-1512. [CrossRef]

11. Wen, G.D.; Ma, T.J.; Li, W.Y.; Li, J.L.; Guo, H.Z.; Chen, D.L. Cyclic deformation behavior of linear friction welded Ti6Al4V joints. Mater. Sci. Eng. A 2014, 597, 408-414. [CrossRef]

12. Buffa, G.; Campanella, D.; Cammalleri, M.; Ducato, A.; Astarita, A.; Squillace, A.; Esposito, S.; Fratini, L. Experimental and numerical analysis of microstructure evolution during linear friction welding of Ti6Al4V. Procedia Manuf. 2015, 1, 429-441. [CrossRef]

13. Maio, L.; Liberini, M.; Campanella, D.; Astarita, A.; Esposito, S.; Boccardi, S.; Meola, C. Infrared thermography for monitoring heat generation in a linear friction welding process of Ti6Al4V alloy. Infrared Phys. Technol. 2017, 81, 325-338. [CrossRef]

14. Jiang, C.Y.; Wu, M.F.; Yu, C.; Liang, C. Morphology and strength of TC4/TC4 joint with 72Ag-28Cu filler metal. Rare Met. Mater. Eng. 2003, 32, 295-297.

15. Wu, Z.; Mei, J.; Voice, W.; Beech, S.; Wu, X. Microstructure and properties of diffusion bonded Ti-6Al-4V parts using brazing-assisted hot isostatic pressing. Mater. Sci. Eng. A 2011, 528, 7388-7394. [CrossRef]

16. Zhang, Y.; Sato, Y.S.; Kokawa, H.; Seung Park, S.H.C.; Hirano, S. Microstructural characteristics and mechanical properties of Ti-6Al-4V friction stir welds. Mater. Sci. Eng. A 2008, 485, 448-455. [CrossRef]

17. Mironov, S.; Zhang, Y.; Sato, Y.S.; Kokawa, H. Development of grain structure in $\beta$-phase field during friction stir welding of Ti-6Al-4V alloy. Scr. Mater. 2008, 59, 27-30. [CrossRef]

18. Buffa, G.; Ducato, A.; Fratini, L. FEM based prediction of phase transformations during friction stir welding of Ti6Al4V titanium alloy. Mater. Sci. Eng. A 2013, 581, 56-65. [CrossRef]

19. Ertek Emre, H.; Kaçar, R. Resistance spot weldability of galvanize coated and uncoated TRIP steels. Metals 2016, 6, 299. [CrossRef]

20. Aslanlar, S.; Ogur, A.; Ozsarac, U.; Ilhan, E. Welding time effect on mechanical properties of automotive sheets in electrical resistance spot welding. Mater. Des. 2008, 29, 1427-1431. [CrossRef]

21. Kazdal Zeytin, H.; Ertek Emre, H.; Kaçar, R. Properties of resistance spot-welded TWIP steels. Metals 2017, 7, 14. [CrossRef]

22. Wu, S.N.; Ghaffari, B.; Hetrick, E.; Li, M.; Liu, Q.; Jia, Z.H. Thermo-mechanically affected zone in AA6111 resistance spot welds. J. Mater. Process. Technol. 2017, 249, 463-470. [CrossRef] 
23. Kahraman, N. The influence of welding parameters on the joint strength of resistance spot-welded titanium sheets. Mater. Des. 2007, 28, 420-427. [CrossRef]

24. Shi, H.X.; Qiu, R.F.; Zhu, J.H.; Zhang, K.K.; Yu, H.; Ding, G.J. Effects of welding parameters on the characteristics of magnesium alloy joint welded by resistance spot welding with cover plates. Mater. Des. 2010, 31, 4853-4857. [CrossRef]

25. Chen, N.N.; Wang, H.P.; Carlson, B.E.; Sigler, D.R.; Wang, M. Fracture mechanisms of Al/steel resistance spot welds in lap shear test. J. Mater. Process. Technol. 2017, 243, 347-354. [CrossRef] 